\title{
FORECASTING AND MONITORING AGRICULTURAL DROUGHT IN THE PHILIPPINES
}

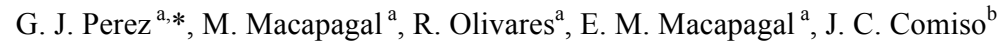 \\ ${ }^{\text {a }}$ Institute of Environmental Science and Meteorology, University of the Philippines Diliman, 1101 Quezon City, Philippines - \\ gpperez1@up.edu.ph, marcomacapagal1@gmail.com, roolivares@up.edu.ph,macapagal.erika@gmail.com \\ ${ }^{\mathrm{b}}$ Earth Sciences Division, NASA Goddard Space Flight Center, Greenbelt, 20771 Maryland - josefino.c.comiso@nasa.gov
}

KEY WORDS: Remote Sensing Applications, Agriculture, Drought, Natural Hazards, Philippines

\begin{abstract}
:
A monitoring and forecasting sytem is developed to assess the extent and severity of agricultural droughts in the Philippines at various spacial scales and across different time periods. Using Earth observation satellite data, drought index, hazard and vulnerability maps are created. The drought index, called Standardized Vegetation-Temperature Ratio (SVTR), is derived using the Normalized Difference Vegetation Index (NDVI) and Land Surface Temperature (LST). SVTR is evaluated by correlating its values with existing agricultural drought index, particulary Evaporative Stress Index (ESI). Moreover, the performance of SVTR in detecting drought occurrences was assessed for the 2015-2016 drought event. This period is a strong El Niño year and a large portion of the country was affected by drought at varying degrees, making it a good case study for evaluating drought indices. Satellitederived SVTR was validated through several field visits and surveys across different major agricultural areas in the country, and was found to be $73 \%$ accurate. The drought hazard and vulnerability maps are produced by utilizing the evapotranspration product of MODIS, rainfall climatology from the Tropical Rainfall Microwave Mission (TRMM) and ancillary data, including irrigation, water holding capacity and land use. Finally, we used statistical techniques to determine trends in NDVI and LST and generate a sixmonth forecast of drought index. Outputs of this study are being assessed by the Philippine Atmospheric, Geophysical and Astronomical Services Administration (PAGASA) and the Department of Agriculture Bureau of Soils and Water Management (DABSWM) for future integration in their operations.
\end{abstract}

\section{INTRODUCTION}

\subsection{Agricultural drought in the Philippines}

Drought is a phenomenon in which the precipitation is below average resulting in prolonged shortages in water supply. Several types of drought has been described in literature but the type we are concerned with is the one known as agricultural drought that leads to negative and severe impacts in agricultural areas, hence food security and associated socio-economic conditions. This type of drought is known to be associated with the lack of water and poor soil management thereby affecting crop growth and lead to reduced yield. Since the Philippines is primarily an agricultural country, with its agricultural lands comprising $32 \%$ of the total land area, ability to monitor drought and provide early warning to farmers and water supply managers is important. In the Philippines, major droughts are offentimes associated with El Niño events, with impacts ranging from crop loss or reduction in yields, water shortage, grass and forest fires to socio-economic problems such as food shortage, loss of income and even increase in crime rates. The 2009-2010 moderate El Niño event led to drought damages amounting to around USD 240 million (Lema and Owen, 2015), while the drought damages caused by a very strong El Niño event in 2015-2016 nearly reached USD 90 million as of February 2016 (FAO, 2016 and Lee-Brago and Flores, 2016). To help the general public and government agencies in managing agricultural lands, crop production and water resources, an objective assessment tool should be available to monitor the extent and severity of drought as it develops. Even more important is the ability to forecast accurately the occurrence of an upcoming drought and the location of severe or vulnerable drought areas.

Studying the dynamics of drought rely largely on data of climate and environmental parameters that affect crop health. Here, we utilized historical and present climate records of weather stations (ground-based) and observations from satellites to investigate the occurrences of drought and the seasonal and annual variability of crops. Past and present observations were used to develop drought index, vulnerabilty and hazard maps to monitor and assess drought affected areas. The satellite-based measurements were also used to develop statistical models for drought forecasts.

\subsection{Satellite-derived drought indicators}

The capability to detect agricultural drought conditions using visible, near infrared and microwave satellite data have been reported previously by Tucker and Choudhury (1987). The study indicates that the vegetation index as provided by visible and near infrared data could detect drought conditions as manifested in deficiencies in the photosynthetic capacity of terrestrial vegetation. Similar information was derived using passive microwave data and most specifically, the polarization difference at $37 \mathrm{GHz}$ channels. The effectiveness of the concurrent use of optical and microwave observations, and also passive and active microwave observations for land surface studies were also described by Choudhury (1994) and Pampaloni (1994), respectively.

* Corresponding author 
The vegetation cover is quantified using the Normalized Difference Vegetation Index (NDVI), which is derived using the equation: NDVI $=\left(\rho_{\mathrm{NIR}}-\rho_{\mathrm{R}}\right) /\left(\rho_{\mathrm{NIR}}+\rho_{\mathrm{R}}\right)$, where $\rho_{\mathrm{R}}$ is the reflectance at $0.65 \mu \mathrm{m}$ (red band), and $\rho_{\mathrm{NIR}}$ is the reflectance at $0.86 \mu \mathrm{m}$ (near infrared band). These two bands are especially useful for vegetation studies because healthy vegetation has high absorption coefficient in the red band while it has high reflection coefficient in the near-infrared band (Tucker 1979). As defined, NDVI represents the photosynthetic capacity of vegetation (Tucker and Sellers 1986) and has been observed to be correlated with ground measurements of biomass, leaf-area index (LAI), intercepted photosynthetically active radiation (IPAR), and other photosynthetic activity (Stow et al., 1993; Myneni and Williams 1994; Carlson and Ripley 1997; Hope et al. 2005; Riedel et al. 2005). Its values from 0.1 to 0.9 indicate different vegetation 'greenness', values around 0 are bare soil while negative values often represent water or clouds (Sobrino and Julien, 2011). The NDVI used in this study is derived from the Moderate resolution Imaging Spectroradiometer (MODIS), which has daily observation data across the country since 2000 .

It is fortuitous that in addition to NDVI, MODIS provides concurrent land surface temperature (LST) data. The availability of such surface temperature data is useful because it enables assessment of how the seasonal and interannual changes in the vegetation are related to changes in surface temperature. Surface temperature, $\mathrm{T}_{\mathrm{S}}$, is derived using surface radiances in the thermal infrared band and the Stefan-Boltzmann equation given by:

$$
\mathrm{R}=\sigma \varepsilon \mathrm{T}_{\mathrm{S}}^{4}
$$

where $\mathrm{R}$ is the radiance at $11 \mu \mathrm{m}$ as derived from MODIS, $\sigma$ is the Stefan-Boltzmann constant and $\varepsilon$ is the emissivity of the surface (Wan and Li, 1997). The emissivity of the surface depends on surface type and is derived from global emissivity maps. To assess and monitor historical and current drought events, anomalies of monthly LST were derived from the MODIS instrument that is onboard Aqua satellite.

In addition to surface temperature, rainfall data that can be derived from passive microwave and radar data are available almost simultaneously with the NDVI dataset (Kummerow et al. 1996; Ferraro et al. 1998; and Adler et al. 2003). Rainfall serves not just as a moderating influence to surface temperature but it is the key factor that leads to the renewal of vegetation and the enhancement of plant growth. Rainfall is the primary driving force of soil moisture and is therefore also an important factor for monitoring and detecting drought. The most comprehensive global rainfall data that are currently available are those derived from the Tropical Rainfall Microwave Mission (TRMM) and other sources, which have been assembled to produce climatological data starting in 1998 (Kummerow et al., 1998). Its successor, the Global Precipitation Measurement Mission (GPM) has produced rainfall data since March 2014.

\section{DROUGHT ASSESSMENT AND FORECASTING TOOLS}

\subsection{Drought Index}

Drought is a naturally occurring phenomenon that can inflict adverse impacts on agriculture, economy and society all over the world. In order to quantitatively assess the impact of devastating drought-induced damages, researchers have (a)

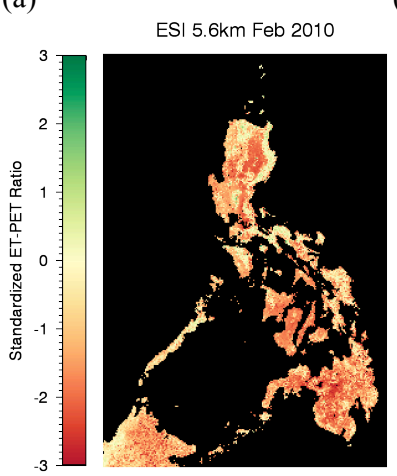

(c)

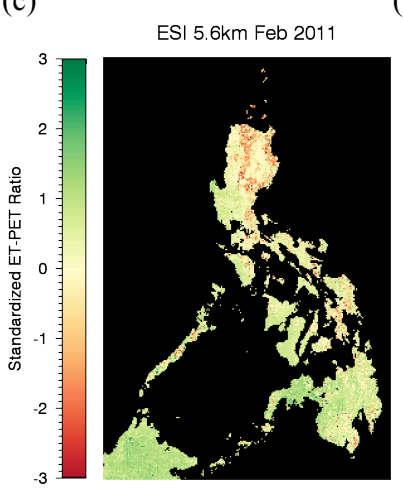

(b)

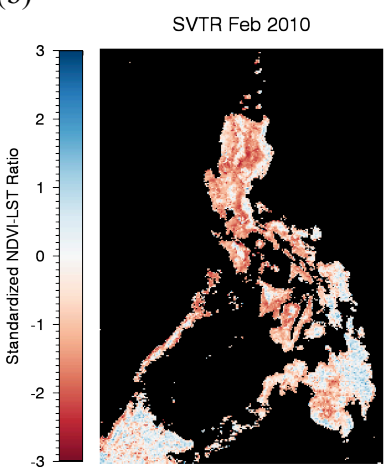

(d)

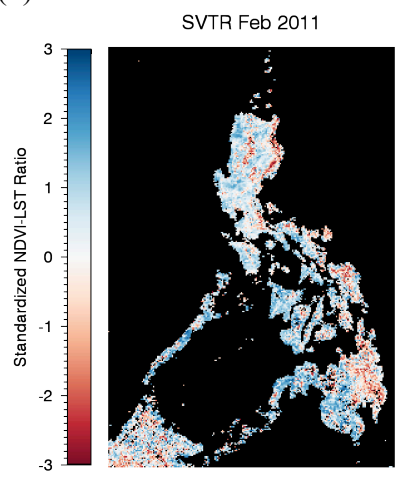

Figure 1. Maps of (a) ESI [5.6 km] and (b) SVTR [5.6 km] for February 2010 and (c) ESI [5.6 km] and (d) SVTR [5.6 km] for February 2011.

developed a variety of drought indices to systematically detect, monitor, and investigate drought events. Specifically, drought indices can be employed to determine drought severity, spatial extent and duration. Moreover, they can be used to evaluate and compare drought events spatiotemporally, as well as provide a basis for drought management for government agencies by helping them define drought thresholds and alarm levels (Niemeyer, 2008). In pursuit of a single, widely accepted drought index, generations of scientists are continuously devising different types of indices that can accurately detect and assess drought events. Unfortunately, a single universally accepted drought index is difficult to develop because of different requirements by different user communities (Wilhite and Glantz, 1985; Niemeyer, 2008).

The Philippine Atmospheric, Geophysical and Astronomical Services Administration (PAGASA) currently uses Standardized Precipitation Index (SPI) and Percent of Normal Precipitation (PNP) as metrics for drought events in the country. Both are rainfall-based drought metrics, hence, they are good measures of meteorological drought. However, according to Wilhite and Glantz (1985), meteorological droughts do not always coincide with periods of agricultural droughts. It is possible that precipitation has resumed after long period of dryness, marking the end of meteorological drought, but the amount of rainfall is still not enough to meet crop water demand, hence, there is still prevailing agricultural drought. On the other hand, despite the presence of meteorological drought the availability of irrigation or other sources of water would prevent the occurrence of agricultural drought. Generally, there is thus a need for a metric capable of quantifying and characterizing agricultural drought events. 
Here, we used the Standardized Vegetation-Temperature Ratio (SVTR) as a localized agricultural drought index. SVTR is defined as:

$$
S V T R=\frac{R_{i}-\bar{R}_{i}}{\sigma_{R}}
$$

where $R_{i}$ is the ratio of NDVI and LST for month $i, \bar{R}_{i}$ is the mean of NDVI-LST ratio for month $i$, and $\sigma_{\mathrm{R}}$ is the standard deviation of NDVI-LST ratio for month $i$. Literature showed that the relationship between NDVI and LST can provide proxy information for soil moisture (Sandholt et al., 2002; Son et al., 2012). Thus, these parameters can be used to assess agricultural drought conditions. Monthly MODIS NDVI and LST products with $5.6 \mathrm{~km}$ spatial resolution, acquired starting August 2002 to present, were used to calculate and produce monthly SVTR maps. Negative SVTR values denote areas with dry conditions.
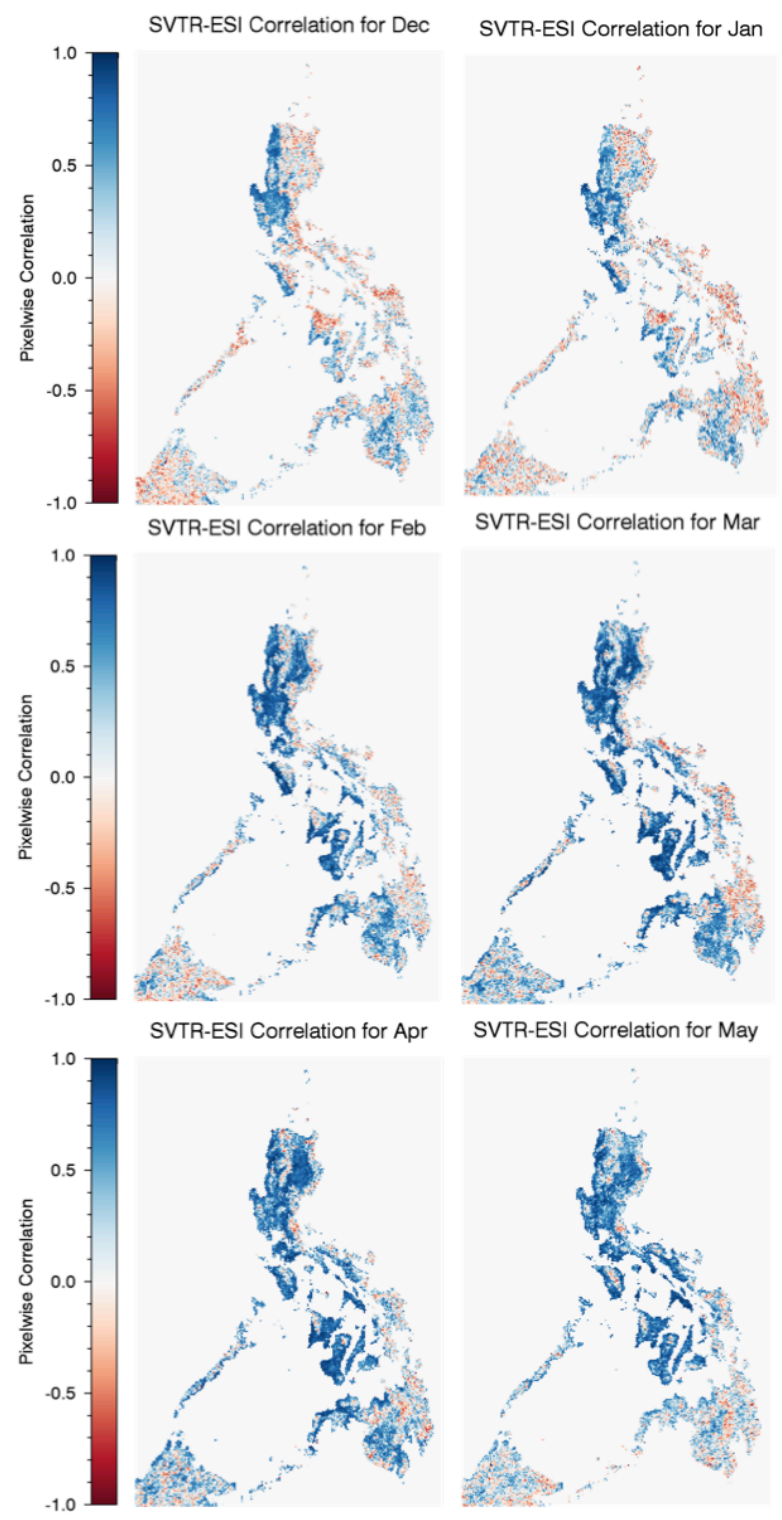

Figure 2. Correlation maps of SVTR and ESI during dry months
In the U.S., the Department of Agriculture (USDA) currently employs an agricultural drought index called Evaporative Stress Index (ESI), which can detect rapid onset of drought events or flash droughts (Otkin et al., 2013; Otkin et al., 2014). ESI denotes standardized anomalies in the ratio of actual evapotranspiration to potential evapotranspiration, indicating areas with anomalously high or low rates of water use across the U.S. Negative ESI signify higher levels of water stress, while positive ones indicate areas of relatively low water stress. The USDA derived ESI values using thermal infrared imagery from geostationary satellites and can produce monthly ESI maps with $4 \mathrm{~km}$ spatial resolution. For this study, MODIS Evapotranspiration products were used to calculate and produce monthly ESI maps with $5.6 \mathrm{~km}$ spatial resolution for the period January 2000 to December 2014.

SVTR and ESI maps with $5.6 \mathrm{~km}$ spatial resolution show striking resemblance considering that the former uses actual and potential evapotranspiration while the latter employs NDVI and LST (Figure 1). Both agricultural drought indices were able to detect drought conditions during February 2010, when a moderate El Niño was prevailing, as well as moist conditions during the 2011 strong La Niña phenomenon. Pixelwise correlation of SVTR with ESI indicated the suitability of the proposed drought index in detecting moisture stress in agricultural lands (Figure 2). SVTR showed high positive correlation with ESI particularly during the dry months of February to May. Stronger positive correlation was also observed in croplands than those in mountainous and forested areas. This may be attributed to the higher sensitivity of agricultural crops to increases in temperature (Perez and Comiso, 2014; Comiso et al., 2014). The low correlation observed in some agricultural areas during the months of December and January is associated with the start of cropping season characterized by low vegetation cover and high soil moisture.

To determine the ability of remotely sensed SVTR in detecting drought occurrences, several ground validation efforts were performed between April 2015 and January 2016. A total of 89 drought reconnaissance points were considered in different parts of the country, namely, Zamboanga City, Bukidnon, North Cotabato, Central Luzon, Negros Occidental, Iloilo, Capiz, and Pangasinan. Actual drought occurrences in these areas were recorded by conducting key informant interviews with local farmers and agriculturists. Specifically, respondents were asked to recollect historical drought occurrences in their respective areas. This information is translated into monthly drought or no drought categories. These ground-based drought data were compared with drought- and non-drought categories determined from the satellite-derived SVTR by applying a threshold, where SVTR $<-0.5$ being defined as drought occurrence. Several statistical scores, namely, accuracy, precision, hit rate, miss rate, specificity, and negative predictive value, were calculated to evaluate the performance of the agricultural drought index. The results showed that SVTR could detect agricultural drought occurrences with an accuracy of $73 \%$ and precision of $92 \%$. Moreover, the satellite-based drought index can correctly identify drought events $74 \%$ of the time, while missing $26 \%$ of actual drought events. 


\subsection{Drought Vulnerability}

Drought vulnerability assessment is a critical component of drought preparedness, mitigation, and management (Wilhelmi and Wilhite, 2002). We developed a nationwide agricultural drought vulnerability map using remote sensing and GIS-based processing techniques. The paramemeters used are land-use system, irrigation support, and soil water holding capacity based on soil texture. Satellite-derived evapotranspiration and rainfall climatologies were also used to supply the necessary information for agricultural drought vulnerability assessment. In previous study NDVI was shown to be highly correlated with temperature (Perez and Comiso, 2015), this effect is accounted for in the estimate of evapotraspiration. A numerical weighing scheme modified from Wilhelmi \& Wilhite (2002) was employed to develop an Agricultural Drought Vulnerability Map (Table 1). Drought vulnerability was estimated using multi-criteria evaluation analysis - weighted linear combination equation:

$$
V=\sum w_{i} x_{i}
$$

where, $\mathrm{V}$ denotes drought vulnerability, $\mathrm{w}_{\mathrm{i}}$ signifies weight of factor $\mathrm{i}$, and $\mathrm{x}_{\mathrm{i}}$ referring to criterion score for factor $\mathrm{i}$.

Agricultural areas in the country were classified into three drought vulnerability categories, namely, low, moderate, and high vulnerability (Figure 3 ). Least vulnerable areas, shown in green, are mostly composed of grasslands or rangelands, where livestocks are bred. These land use types are less vulnerable to drought because most grass species can withstand low rainfall and extremely high surface temperature as compared to agricultural crops, particularly rice and corn, which require intensive water supply and moderate surface temperature. Moreover, high climatological evapotranspiration rates also contributed to low vulnerability of rangelands. Low drought vulnerable areas can be found in Bohol and some parts of Mindanao, particularly in Surigao del Sur, Agusan del Norte, Agusan del Sur, Davao del Norte and Compostella Valley (Figure 3). This condition can be associated with the presence of irrigation infrastructures (BSWM, 2013), high rainfall rates (NASA/GES DISC), as well as soil texture conducive (BSWM, 2013) for vegetation growth.

\begin{tabular}{|c|c|c|c|}
\hline $\begin{array}{c}\text { Vulnerability } \\
\text { factor }\end{array}$ & Weight & $\begin{array}{c}\text { Vulnerability } \\
\text { class }\end{array}$ & $\begin{array}{c}\text { Criterion } \\
\text { Score } \\
\end{array}$ \\
\hline \multirow[t]{2}{*}{ Access to irrigation } & \multirow[t]{2}{*}{0.40} & Irrigated & 2 \\
\hline & & Rainfed & 4 \\
\hline \multirow{4}{*}{$\begin{array}{l}\text { Available soil- } \\
\text { water holding } \\
\text { capacity } \\
\text { (mm water / m } \\
\text { soil) }\end{array}$} & \multirow[t]{4}{*}{0.30} & $>200$ & 1 \\
\hline & & $150-200$ & 2 \\
\hline & & $100-150$ & 3 \\
\hline & & $<100$ & 4 \\
\hline $\begin{array}{l}\text { Climatological } \\
\text { Evapotranspiration } \\
(\mathrm{mm} / \mathrm{month})\end{array}$ & 0.15 & $42-294$ & $\begin{array}{l}-4.13- \\
10.43^{*}\end{array}$ \\
\hline $\begin{array}{l}\text { Climatological } \\
\text { Precipitation } \\
(\mathrm{mm} / \mathrm{hr}) \\
\end{array}$ & 0.15 & $13-59$ & $\begin{array}{c}-2.38- \\
4.04 *\end{array}$ \\
\hline
\end{tabular}

Table 1. Numerical weighing scheme used to develop the Philippine Agricultural Drought Vulnerability Map (Modified from Wilhelmi \& Wilhite, 2002)

*Scores for evapotranspiration and rainfall climatologies were standardized.
Moderate drought-prone areas shown in yellow are mostly composed of croplands with access to national irrigation systems, dams, and other water reservoirs, as illustrated in Figure 3. Moderately-vulnerable areas in Isabela are being supplied with water by several National Irrigation Systems,
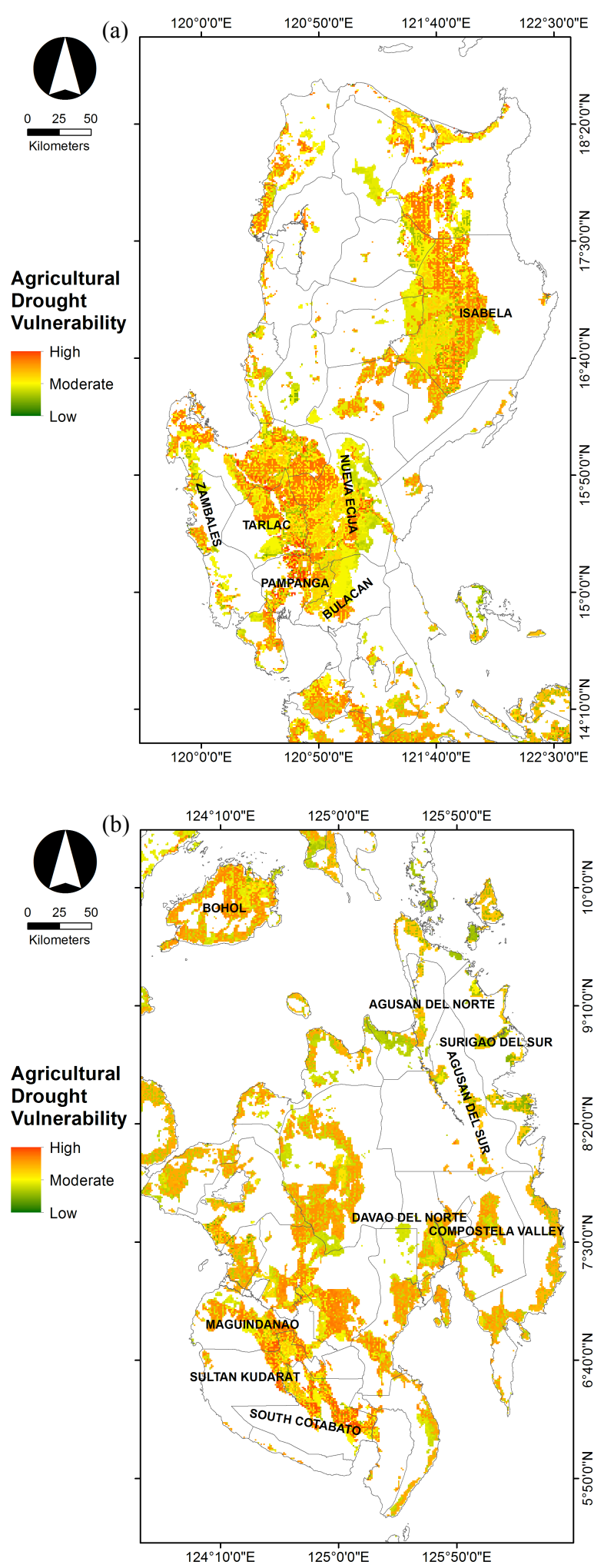

Figure 3. Agricultural drought vulnerability in some parts of (a) Cagayan Valley and Central Luzon and (b) Bohol and Mindanao. 
including San Pablo-Cabagan, Tumauini, Upper Chico, and Mallig River Irrigation Systems, among others. In addition, extensive rice fields in Nueva Ecija, Tarlac, and portions of Pampanga, Zambales and Bulacan, are continuously being serviced by different dams, rivers and irrigation systems, including the Angat-Masim River Irrigation System, Angat and Bustos dams, Tarlac diversion dams, Camiling River Irrigation System, as well as Bagsit and Camachile dams (BSWM, 2013).

Agricultural areas that are highly vulnerable to drought impacts are shown in red. These croplands rely exclusively on rainfall for water supply and are not being serviced by any irrigation systems and water reservoirs. Either there are no irrigation infrastructures available or they are being serviced by underperforming ones. The most vulnerable croplands can be observed in some parts of Central Luzon, as well as some parts of Central Mindanao (Figures 3). Even though there are several dams and irrigation infrastructures located in Central Luzon, sandy and other coarse-textured soil are predominant soil types, particularly in Pampanga and Tarlac. This condition could be attributed to the Mt. Pinatubo erruption, which changed the soil texture profile into a soil type that cannot hold enough water to sustain crop growth. Moreover, the relatively-low climatological evapotranspiration rate makes the condition even worse. Similarly, South Cotabato, Maguindanao, and Sultan Kudarat have large number of irrigation systems, but are still very prone to drought due to the low available water holding capacity of their soils. Such conditions are made worse by the low average rainfall rate in Central Mindanao.

\subsection{Drought Hazards}

Hazard is defined as an event that poses a threat to a community (Knutson et al., 1998). In the context of drought, this translates to the reduction of water supply. To measure the likelihood of drought, the revised ESI (RESI) was used, which assessed the presence and severity of drought events. ESI developed to detect flash droughts (Otkin et al., 2013) was modified by computing the standardization based on the entire time series instead of calculating it for each month. This will capture the month-to-month variability in the local conditions of the environment. Evapotranspiration data from MODIS for the period January 2000 to December 2014 were used to derive RESI. The drought hazards were computed by employing the Peaks-over-threshold (POT) approach based on extreme value theory. Drought hazard maps were then derived from the computed likelihood of drought events.

The Peaks-over-threshold (POT) approach estimates the parameters of the conditional distribution $F$ of the random variable $X$,

$$
F_{u}(y)=\mathrm{P}(Y=X-u \mid X>u)
$$

where $u$ is the threshold separating the extreme values from the non-extreme values of the random variable $X, y=x-u$ are the exceedances from $u$ and $x_{F}<\infty$ is the upperbound of $F$ (McNeil et al., 2005). Here, the random variable $X$ corresponds to RESI.

The POT approach starts with the selection of threshold $u$ based on the L-moment plot, threshold choice plot, and dispersion index plot (McNeil et al., 2005). For this study, the threshold was determined to be -1 . All values of RESI falling below this threshold were identified as extreme values. The parameters of the probability distribution function defined in equation (4) were estimated based on the observed exceedances. (a)

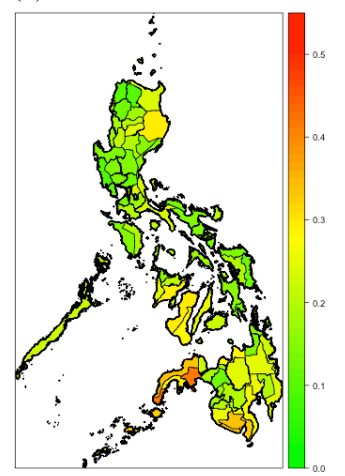

(c)

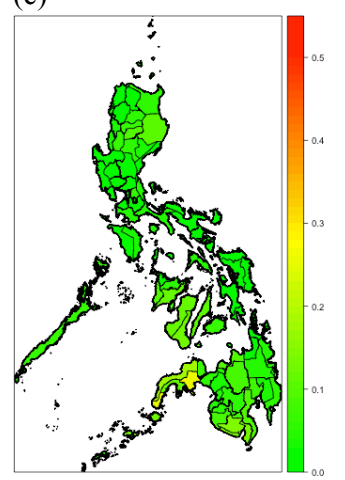

(b)

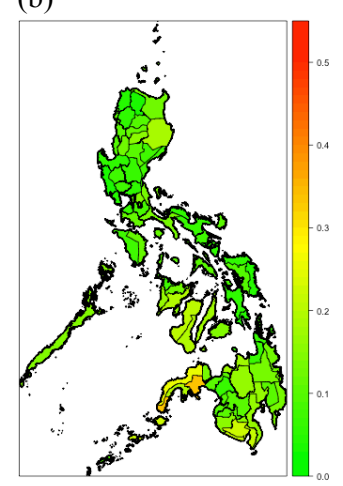

(d)

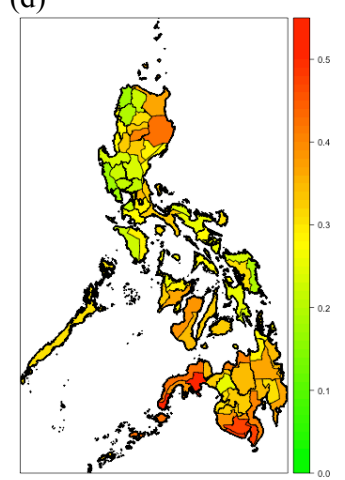

Figure 4. Drought probabilities for (a) near-normal, (b) moderate, (c) severe and (d) all kinds of drought events.

Pareto distribution (GPD) function was used to compute the probability of exceedances, which denotes drought hazards.

The drought hazard maps in Figure 4 show the drought probabilities in different provinces in the country. The regions with hues of red indicate higher probabilities of drought making them more prone to drought occurrences. Figure 4a shows that near normal drought $(\operatorname{RESI}=(-2,-1])$ are highly likely to occur in the Zamboanga Peninsula, Southern Mindanao, Central Mindanao, Negros Island Region, Iloilo and Isabela. Figures $4 \mathrm{~b}$ and $4 \mathrm{c}$ indicate that moderate $(\operatorname{RESI}=(-3,-2])$ to severe $(\operatorname{RESI}$ $\leq-3)$ drought are still likely to happen in the Zamboanga Peninsula. Figure $4 \mathrm{~d}$ shows that drought events of varying severity are expected to happen in the general area of Mindanao, Western and Central Visayas and Cagayan Valley in Luzon.

\subsection{Drought Forecast}

Different statistical methods were used to forecast LST and NDVI, and consequently generate a forecast for SVTR. Inputs of the statistical models are historical LST and NDVI values, as well as Oceanic Niño Index (ONI) from the IRI/CPC. Soil moisture (SM) and rainfall (RF) were also included in some of the modeling procedures to forecast LST and NDVI. The different statistical models and procedures used in this study are: autoregressive integrated moving average (ARIMA) models, canonical correlation analysis (CCA), vector autoregressive (VAR) models, artificial neurological networks (ANN) and multiple linear regression (MLR). The four models were then combined using local regression to get a robust final ensemble forecast. 


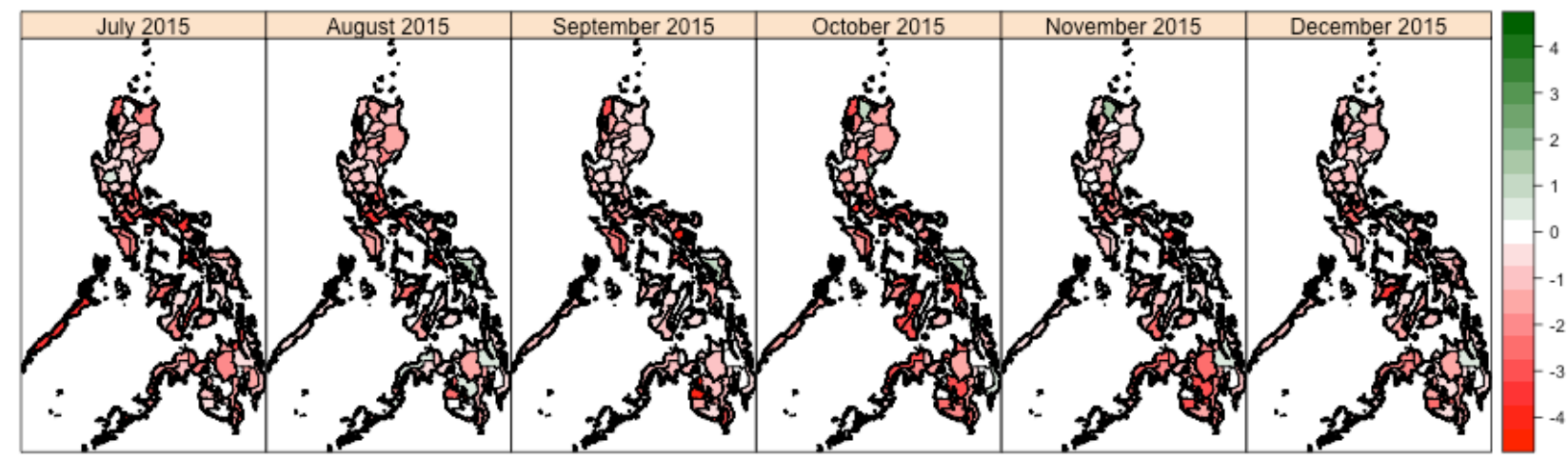

Figure 5. SVTR forecast from July to December 2015.

Figure 5 shows the SVTR forecast for July 2015 until December 2015. This six-month forecast was generated using MODIS NDVI and LST values from July 2002 to June 2015 and ONI values from July 2002 to December 2015. The maps indicate that a large portion of the county will experience varying levels of drought during this period. This is somehow expected since these months correspond to the peak of El Niño. To assess the accuracy of our forecast, the root-mean-square error (RMSE) was computed based on the actual SVTR values derived from satellite observations. Results show that there is a good agreement between the forecasted and actual SVTR with RMSE values ranging from 1.03 to 1.6 (Figure 6). Further analysis of the performance of the forecasts for each month of the year at different lag times revealed that forecast error is increasing from one month to four months lag. This is expected, knowing that forecasts become less reliable as we go farther from the point of initialization. Moreover, forecasts for dry months, specifically February until May, has the lowest errors compared to other months of the year. This can be attributed to the relatively low variation of vegetation and temperature during these months.

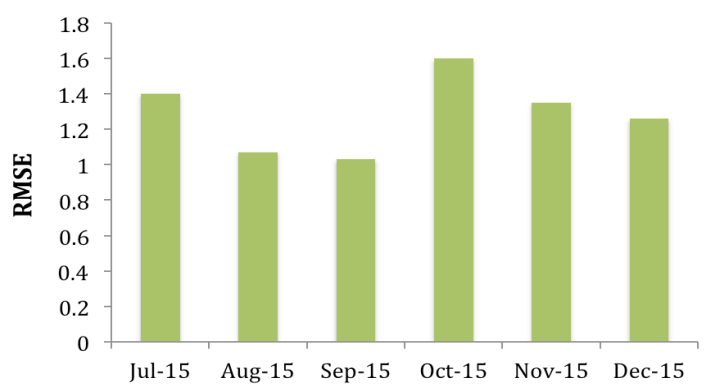

Figure 6. Root-mean-square error between forecasted and observed SVTR.

\section{CONCLUSION}

Agricultural drought in the Philippines has been studied using primarily NDVI and LST derived from EOS/Terra and Aqua/MODIS data from 2000 to 2016. The key parameter used in the study is the Standardized Vegetation-Temperature Ratio (SVTR) drought index, which makes use of the ratio of NDVI and LST. Using ground based drought data that are derived primarily from detailed interviews with farmers, SVTR provides information about the occurrence of drought at an accuracy of $73 \%$ and a precision of $92 \%$. SVTR is also shown to be highly correlated with the Evaporative Stress Index (ESI), used by the US Department of Agriculture for detecting drought events, during the dry months of April and May. The vulnerability of different crop areas all over the Philippines was also evaluated using a drought vulnerability factor that depends on access to irrigation, water holding capacity of the soil, climatological evapotranspiration and climatological precipitation rate. The most vulnerable croplands are parts of Central Luzon and Central Mindanao. A revised Evaporative Stress Index (RESI) was also used to assess the likelihood of the occurrence of drought and to create drought hazard maps. Finally, a combined statistical regression model was used to forecast the occurrence of a future drought, using SVTR, and the results show good agreement with actual drought events with RMSE values ranging from 1.03 to 1.6 .

\section{ACKNOWLEDGEMENTS}

The authors would like to thank the following satellite data providers: the Goddard Earth Sciences Data and Information Services Center (GES DISC) of NASA ["The data used in this effort were acquired as part of the activities of NASA's Science Mission Directorate, and are archived and distributed by the Goddard Earth Sciences (GES) Data and Information Services Center (DISC)."], NASA Land Processes Distributed Active Archive Center (LP DAAC), USGS/Earth Resources Observation and Science (EROS) Center. This study was funded by the Department of Science and Technology (DOST) through the Drought and Crop Assessment and Forecasting (DCAF) Project.

\section{REFERENCES}

Adler, R. F., Huffman, G. J., Boivin, D. T., Curtis, S.,and Nelkin, E. J., 2000. Tropical Rainfall Distributions determined using TRMM combined with other satellite and rain gauge information. Journal of Applied Meteorology, 39: pp. 20072023.

BSWM, 2013. National Capability Building for Philippine Land Degradation Assessment and Climate Change Adaptation (FAO/TCP/PHI/3302).

Carlson, T. N. and Ripley, D. A., 1997. On the relation between NDVI, fractional vegetation cover, and leaf area index. Remote Sensing of the Environment, 62: pp. 241-252.

Choudhury, B. J., 1994. Synergism of optical and microwave observations for land surface studies, In: Passive Microwave Remote Sensing of Land-Atmosphere Interactions, eds. B. J. 
Choudhury, Y. H. Kerr, E. G. Njoku, and P. Pampaloni, VSP BV, Netherlands, pp.155-192.

Comiso, J.C., Blanche, C.A., Sarigumba, T.I., Espaldon, M.V.O., Lansigan, F.P., Baguino, N.T., Birosel., R.C., Coladilla, J.O., Cruz, R.V.O., Florece, L.M., Guerrero, R.D., Lasco, R.D., Perez, R.T., Pulhin, J.M., and Tibig, L.V, 2014. Changing Philippine Climate: Impacts on Agriculture and Natural Resources. Quezon City, Philippines: University of the Philippines Press.

FAO, 2016. 2015-2016 El Niño Early action and response for agriculture, food security and nutrition. Food and Agriculture Organization of the United Nations. Working Draft (15 Mar.2016) FAO, Rome

Ferraro, R.R., Smith, E.A., Berg, W., and Huffman, G.J., 1998. A screening methodology for passive microwave precipitation retrieval algorithms. Journal of Atmospheric Science, 55: pp. $1583-1600$.

Hope, A., Engstrom, D.R. and Stow, D.A., 2005. Relationship between AVHRR surface temperature and NDVI in Arctic tundra ecosystems. International Journal of Remote Sensing, 26: pp. 1771-1776.

Knutson, C., Hayes, M., and Phillips, T., 1998. How to reduce drought risk, Preparedness and Mitigation Working Group of the Western Drought Coordination Council, Lincoln, Neb. (http://drought.unl.edu/ handbook/risk.pdf).

Kummerow, C., Olson, W. S., and Giglio, L., 1996. A simplified scheme for obtaining precipitation and vertical hydrometer profiles from passive microwave sensors. IEEE Trans. Geosci. Remote Sens., 34: pp. 1213-1232.

Kummerow, C., Barnes, W., Kozu, T., Shiue, J., and Simpson, J., 1998. The tropical rainfall measuring mission (TRMM) sensor package. Journal of Atmospheric and Oceanic Technology, 15: pp. 809-817.

Lee-Brago, P. and Flores, H., (2016, February 21). El Niño begins decline. The Philippine Star. Retrieved from http://www.philstar.com/

Lema, K. and Owen, N., (2015, September 15). Philippines' ecconomy to wilt from heat of El Nino. Reuters. Retrieved from http://www.reuters.com/

Myneni, R.B. and Williams, D.L., 1994. On the relationship between FAPAR and NDVI. Remote Sensing of Environment,49(3): pp. 200-211.

NASA/GES DISC: TRMM TMPA 3B42, version 7 . NASA/Goddard Earth Sciences Data and Information Services Center. Subset used: January 1998-January 2016.

Niemeyer S., 2008 New drought indices. In Lopez-Francos A. (ed.). Drought management: scientific and technological innovations. Zaragoza: CIHEAM, pp. 267-274.

Otkin, J.A., Anderson, M.C., Hain, C., Mladenova, I.E., Basara, J.B., and Svoboda, M., 2013. Examining rapid onset drought development using the thermal infrared-based Evaporative Stress Index. Journal of Hydrometeorology, 14: pp. 1057-1074.

Otkin, J.A., Anderson, M.C., Hain, C., and Svoboda, M., 2014. Examining the relationship between drought development and rapid changes in the Evaporative Stress Index. Journal of Hydrometeorology, 15: pp. 938-956.

Sandholt, I., Rasmussen, K., \& Andersen, J. 2002. A simple interpretation of the surface temperature/vegetation index space for assessment of surface moisture status. Remote Sensing of Environment, 79: pp. 213-224

Pampaloni, P., 1994. Sensitivity of active and passive microwave sensors to land parameters, In: Passive Microwave Remote Sensing of Land-Atmosphere Interactions, eds. B. J. Choudhury, Y. H. Kerr, E. G. Nioku, and P. Pampaloni, VSP BV, Netherlands, pp. 95-116.

Perez, G.J. and Comiso, J.C., 2015. Seasonal and Interannual Variability of Philippine Vegetation as Seen from Space. Philippine Journal of Science, 143(2).

Riedel, S.M., Epstein, H.E. and Walker, D.A., 2005: Biotic controls over spectral reflectance of Arctic tundra vegetation. International Journal of Remote Sensing, 26: pp. 2391-2405.

Sobrino, J.A. and Julien, Y.,2011. Global trends in NDVIderived parameters obtained from GIMMS data. International Journal of Remote Sensing, 32(15), pp. 4267-4279.

Son, N.T., Chen, C.F., Chen, C.R., Chang, L.Y., and Minh, V.Q., 2012. Monitoring agricultural drought in the Lower Mekong Basin using MODIS NDVI and land surface temperature data. International Journal of Applied Earth Observation and Geoinformation, 18: pp. 417-427.

Stow, D., Hope, A., and George, T., 1993. Reflectance characteristics of Arctic Tundra vegetation from aerial radiometry and videography. International Journal of Remote Sensing, 14: pp. $1239-1244$.

Tucker, C. J., 1979. Red and photographic infrared linear combinations for monitoring vegetation. Remote Sensing of Environment, 8(2): pp. 127-150.

Tucker, C. J. and Choudhury, B. J., 1987. Satellite remote sensing of drought conditions. Remote Sensing of Environment, 23: pp. 243-251.

Tucker, C.J. and P.J. Sellers (1986) Satellite remote sensing of primary Production. International Journal of Remote Sensing, 7, pp.1395-1416.

Wan, Z., and Li, Z.-L., 1997. A physics-based algorithm for retrieving land-surface emissivity and temperature from EOS/MODIS data. IEEE Trans. Geoscience and Remote Sensing, 35: pp. 980-996.Wilhelmi, O.V. and Wilhite, D.A., 2002. Assessing Vulnerability to Agricultural Drought: A Nebraska Case Study. Natural Hazards, 25: pp. 37-58.

Wilhite, D.A. and Glantz, M.H., 1985. Understanding the drought phenomenon: The role of definitions. Water International, 10(3): pp. 111-120. 